\title{
Relocation of the 2006 Pingtung Earthquake sequence and seismotectonics in Southern Taiwan
}

\author{
Yih-Min Wu ${ }^{\text {a,* }}$, Li Zhao ${ }^{\mathrm{b}}$, Chien-Hsin Chang ${ }^{\mathrm{c}}$, Nai-Chi Hsiao ${ }^{\mathrm{c}}$, Yue-Gau Chen ${ }^{\mathrm{a}}$, Shu-Kun Hsu ${ }^{\mathrm{d}}$ \\ a Department of Geosciences, National Taiwan University, Taipei 10617, Taiwan \\ b Institute of Earth Sciences, Academia Sinica, Nankang, Taipei 115, Taiwan \\ c Central Weather Bureau, Taipei 100, Taiwan \\ d Institute of Geophysics, National Central University, Chungli, Taiwan
}

\section{A R T I C L E I N F O}

\section{Article history:}

Received 20 June 2008

Received in revised form 29 October 2008

Accepted 1 December 2008

Available online $\mathrm{xxxx}$

\section{Keywords:}

Taiwan

Pingtung Earthquake

Traveltime tomography

Subduction zone

\begin{abstract}
A B S T R A C T
We combine the arrival time data from eleven ocean bottom seismometers (OBS) and from permanent stations of the Central Weather Bureau Seismic Network (CWBSN) and the Taiwan Strong Motion Instrumentation Program (TSMIP) to improve the three-dimensional Vp and Vp/Vs structures in the Taiwan region, relocate hypocenters of earthquakes in southern Taiwan including the 2006 Pingtung Earthquake sequence, and determine the focal mechanisms of some of the larger events. Our tomography result suggests that in the region south of Taiwan the Eurasian continental lithosphere is being subducted beneath the oceanic Philippine Sea plate, leading to a region of low P-wave speed with seismicity on top of a relatively high P-wave speed zone. The hypocentral distribution of the Pingtung Earthquake sequence indicates that the first event in the initial two largest shocks was a normal-faulting quake caused by the bending of the subducting lithosphere. The second event, perhaps triggered by the first one, was a strike-slip earthquake.

Crown Copyright @ 2008 Published by Elsevier B.V. All rights reserved.
\end{abstract}

\section{Introduction}

The Pingtung Earthquake sequence started on December 26, 2006. The first shock occurred at 12:26 UTC (20:26 local time). According to the Taiwan Central Weather Bureau (CWB) catalog, the epicenter is located at $21.67^{\circ} \mathrm{N}$ and $121.56^{\circ} \mathrm{E}$, off the southwest coast of Taiwan (Fig. 1), with a focal depth of about $44 \mathrm{~km}$ and a magnitude of $M_{\mathrm{L}}=7.0$ $\left[M_{\mathrm{W}}=7.0\right.$ in the Harvard centroid-moment tensor (CMT) catalog]. It was followed by another big event $8 \mathrm{~min}$ later at $21.97^{\circ} \mathrm{N}$ and $121.42^{\circ} \mathrm{E}$, about $36 \mathrm{~km}$ to the north-northeast of the first shock, with a magnitude of $M_{\mathrm{L}}=7.0\left(M_{\mathrm{w}}=6.9\right.$ in the Harvard CMT catalog $)$ and a focal depth of $50 \mathrm{~km}$. These two large events of comparable size occurring in a very close spatial and temporal proximity formed a doublet (e.g., Lay and Kanamori, 1980). This doublet event caused 44 injuries, including 2 fatal ones, 3 building collapses, and the rupture of submarine communications cables (National Disaster Prevention and Protection Commission, R.O.C., 2007).

One day after the occurrence of the doublet event, a temporary network of 11 ocean-bottom seismometers (OBS) was deployed in the epicentral region from Dec. 27, 2006 to Jan. 3, 2007 to monitor the aftershocks. Fig. 2 shows the locations of the OBSs. The seismicity related to the Pingtung Earthquake represents the largest earthquake sequence in this region in the past one hundred years of recorded

\footnotetext{
* Corresponding author. No. 1, Sec. 4th, Roosevelt Rd., Dept. of Geosciences, National Taiwan Univ., Taipei, Taiwan. Tel.: +88622362 0054; fax: +88622364 4625 .

E-mail address: drymwu@ntu.edu.tw (Y.-M. Wu).
}

seismic activity. Valuable seismograms recorded by the OBS network improved the path coverage in this region tremendously and are extremely helpful to enhancing the resolution of tomography inversions for the source region and to accurately determining the locations of the aftershocks. In this study, we extend the tomography inversions for the Taiwan region in Wu et al. (2007) by incorporating the P-wave arrival times as well as S-P times obtained from the OBS records to improve the resolution and reliability of the threedimensional (3D) Vp and Vp/Vs structures in the Pingtung Earthquake area. Then we use the newly derived 3D structural model to relocate the regional earthquakes from 1991 to 2007, including the events in the Pingtung Earthquake sequence, to examine the seismotectonics of this region, in particular the seismogenic structures associated with the subduction zone along the Manila trench.

\section{Background seismicity}

Based on the faulting characteristics and regional tectonics, the seismicity in and around Taiwan can be divided into western, southwestern, northeastern and southeastern seismogenic zones (Wu and Chen, 2007; Wu et al., 2008a,b). The Pingtung Earthquake sequence is located in the southwestern seismic zone. The event distribution and focal mechanisms in Fig. 1 reveal that the southwestern seismic zone is located in the boundary region between the Philippine Sea Plate and the South China Sea block of the Eurasian Plate. Seismically, it is the least active zone among the four, and most earthquakes in this region have focal depths greater than $30 \mathrm{~km}$ with 


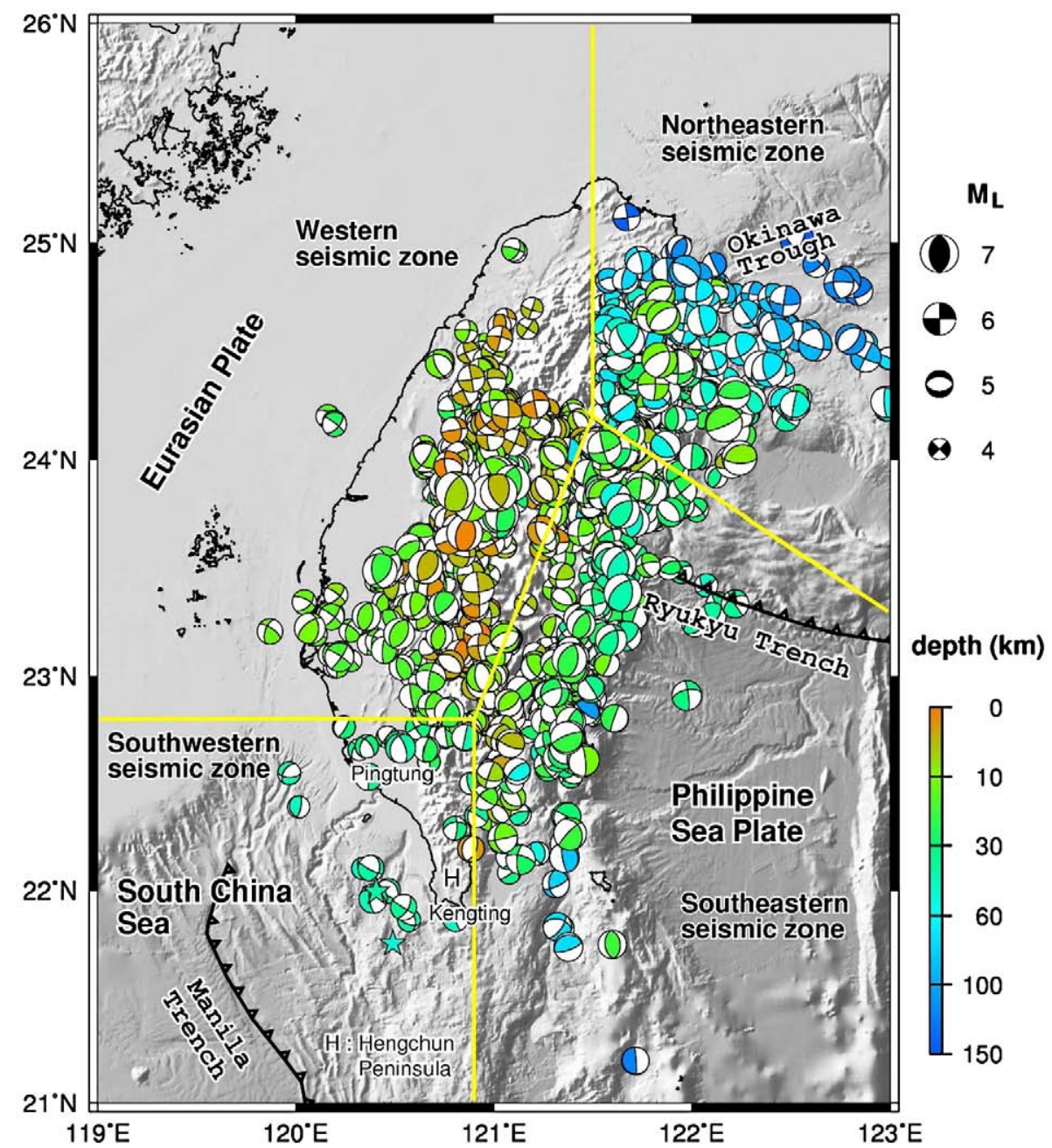

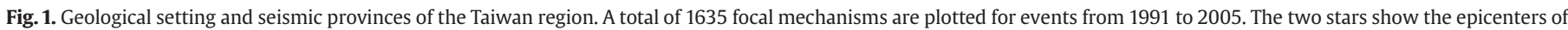
the doublet events in the Pingtung Earthquake.

normal-faulting mechanisms. The normal-faulting earthquakes in this zone are likely associated with the bending of the plunging slab (Wu et al., 2008a,b).

\section{Improved Taiwan regional 3D velocity model}

There have been a number of studies on the 3D structure in the Taiwan region in the past two decades (e.g. Roecker et al., 1987; Rau and Wu, 1995; Ma et al., 1996; Kim et al., 2005; Wang et al., 2006). More recently, Wu et al. (2007) derived the regional 3D Vp and Vp/Vs structures by supplementing the P- and S-wave arrival times from the Central Weather Bureau Seismic Network (CWBSN) stations with a large set of S-P times obtained from the records at 680 stations deployed throughout the island under the Taiwan Strong-Motion Instrumentation Program (TSMIP). The distributions of the CWBSN and TSMIP stations are shown in Fig. 2. The dense distribution of the TSMIP stations improves the source-station path coverage tremendously, leading to better constraints and resolution in velocity structure inversions, especially in the shallow part of the crust. However, almost all of the stations of the CWBSN and TSMIP networks are located on the main island. They cannot provide a good coverage for the off-shore earthquakes such as those in the Pingtung Earthquake sequence. The 11 OBSs (Fig. 2) deployed after the doublet earthquakes filled a crucial gap in the path coverage in the Pingtung offshore region. In this experiment, the MicrOBS (Auffret et al., 2004) has been used with 24-bits resolution and $125-\mathrm{Hz}$ sampling rate. The MicrOBSs are all equipped with a low-drift temperature compensation clock. Before and after the deployment the OBS clocks were calibrated with the GPS time. After seven days of deployment the drifts of the 11 OBS clocks ranged from 34 to $728 \mathrm{~ms}$, with an average of $313 \mathrm{~ms}$ and a standard deviation of $218 \mathrm{~ms}$. The OBS timing was linearly calibrated with the GPS clock and we conclude that the timing errors of the OBS records should be less than $10 \mathrm{~ms}$. As an emergency deployment for the purpose of risk assessment following a large earthquake, the locations of the OBSs were not carefully determined. We took the averages of the deployed and retrieved points as the OBS locations.

In this study, we incorporate the arrival time data from the OBS records to enhance the resolution to the velocity structure in the Pingtung Earthquake source region. A total of 2732 P-wave arrival times and 1916 S-P times from 378 earthquakes were obtained manually from the OBS records. The OBS readings were combined with the dataset used in Wu et al. (2007) in a joint tomography inversion for regional Vp and Vp/Vs structures. Fig. 3 shows the OBS seismograms from one event. $\mathrm{P}$ and $\mathrm{S}$ arrivals can be clearly identified in these records.

The velocity model is specified on a set of 3D spatial grid points, and a linear interpolation is adopted for the structural parameters between the grid points. Vertically we use a total of 17 grid points at the depths of $0,2,4,6,9,13,17,21,25,30,35,50,70,90,110,140$, and $200 \mathrm{~km}$. The horizontal grid is uneven (see Fig. 2). The Taiwan main 


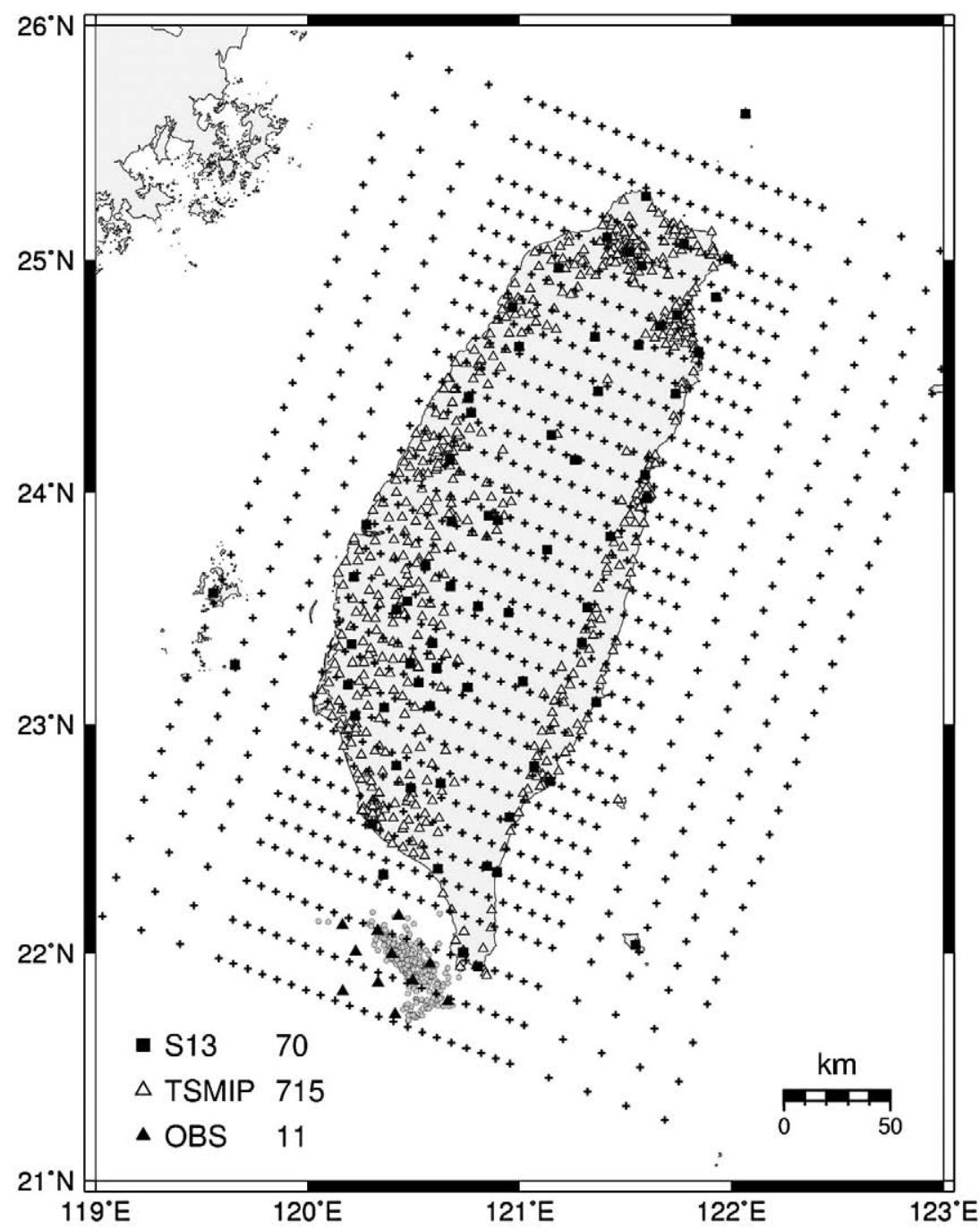

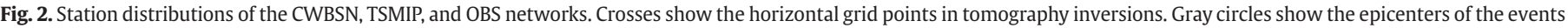
recorded by both the OBS and CWBSN networks.

island is covered by a denser grid with grid spaces of $7.5 \mathrm{~km}$ in the more east-west direction and $12.5 \mathrm{~km}$ in the more north-south direction. This 3D spatial grid is the same as that in Wu et al. (2007), except for the grid points on the most southwestern of the model. The extra plane of grid points are added so as to include all the aftershocks and the OBSs inside the model volume.

In structural inversions we used the algorithm SIMULPS12 (Evans et al., 1994) based on the inversion method of Thurber $(1983,1993)$, Eberhart-Phillips (1990), and Thurber and Eberhart-Phillips (1999). Ray tracing is accomplished by an approximate 3D algorithm with curved non-planar ray paths (Um and Thurber, 1987). The dampedleast-squares inversion is based on the parameter separation technique of Pavlis and Booker (1980).

The damping values in the tomography inversions for $\mathrm{Vp}$ and $\mathrm{Vp} /$ Vs were chosen to be 35 and 40, respectively, the same as in our previous study (Wu et al., 2007). These values were determined from the tradeoff curve between the data misfit and the model variance after running a series of single-iteration inversions with different damping values (Eberhart-Phillips, 1986, 1993). A consistent damping was used in the entire iterative inversion process. Our previous 3D model (Wu et al., 2007) was used as the initial model in the velocity inversion. The initial model parameters on the extra grid points on the most southwestern side were specified using a linear extrapolation from the original 3D model. The structural inversion reached convergence after three iterations. The result is largely similar to our previous one (Wu et al., 2007), with an improved resolution in the southwestern offshore region thanks to the enhanced path coverage provided by the aftershocks and the OBS records.

Fig. $4 \mathrm{~A}$ and $\mathrm{B}$ shows the resolution test results. We constructed the checkerboard velocity models with the same level of velocity variation $( \pm 10 \%)$ and block size $(22.5 \mathrm{~km} \times 37.5 \mathrm{~km} \times 8 \mathrm{~km})$ as in our previous study (Wu et al., 2007). Fig. 4A shows a few horizontal and vertical slices of input and recovered models for the P-wave velocity structures in the checkerboard resolution test (CRT). In this study, we included most of the data used in Wu et al. (2007), thus a good recovery of the P-wave structure underneath Taiwan is achieved. In the southeastern subduction zone the zone of good recovery extends to the depth of about $120 \mathrm{~km}$ (e.g. Profiles $\mathrm{BB}^{\prime}, \mathrm{CC}^{\prime}$, and $\mathrm{DD}^{\prime}$ in Fig. $4 \mathrm{~A}$ ). In the region where the OBS's were deployed, good recovery extends down to 70km depth ( $A A^{\prime}$ and $E E^{\prime}$ in Fig. $4 A$ ) owing to the arrival times from the 2006 Pingtung Earthquake sequence, especially data from the OBS records. In Fig. 4, yellow dashed lines show the resolution improved region. Fig. 4B shows the horizontal and vertical slices of the input and recovered $\mathrm{Vp} / \mathrm{Vs}$ models in the CRT. The arrival times of S-waves are generally more difficult to determine than those of $\mathrm{P}$ waves. Therefore, the recovery of $\mathrm{Vp} / \mathrm{Vs}$ structure is not as good as that of $\mathrm{Vp}$ as shown in 


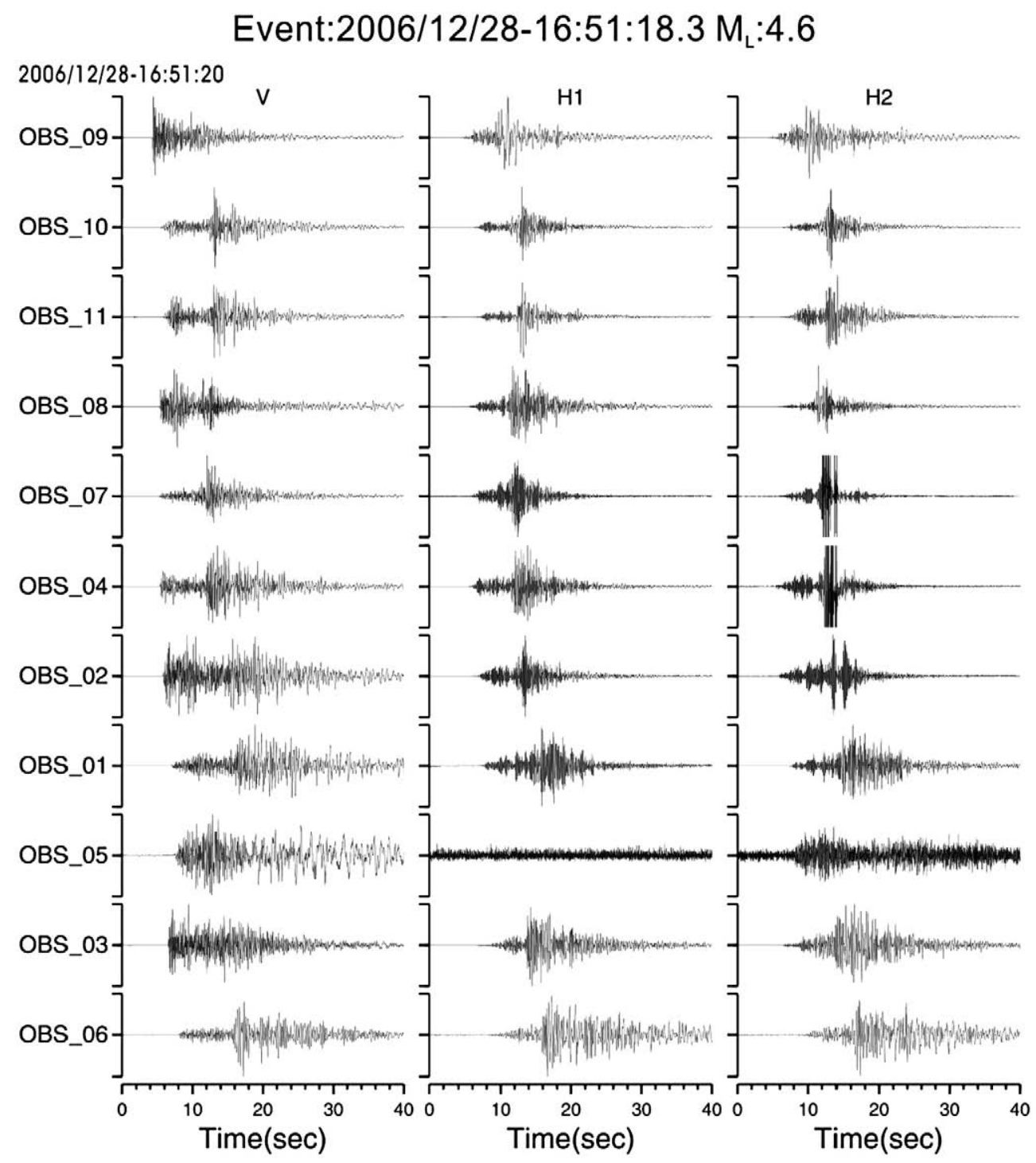

Fig. 3. Samples of OBS seismograms from a $M_{\mathrm{L}} 4.6$ event in the Pingtung Earthquake sequence.

Fig. 4A. However, the region of good $\mathrm{Vp} / \mathrm{Vs}$ recovery can still extend to the depth of $100 \mathrm{~km}$ in the southeastern subduction zone (e.g. Profiles $\mathrm{BB}^{\prime}, \mathrm{CC}^{\prime}$ and $\mathrm{DD}^{\prime}$ in the Fig. $4 \mathrm{~B}$ ) and to $70-\mathrm{km}$ depth in the region where the OBS's are deployed ( $\mathrm{AA}^{\prime}$ and $\mathrm{EE}^{\prime}$ in Fig. $\left.4 \mathrm{~B}\right)$.

\section{Velocity structures and seismicity in southern Taiwan}

After the tomography inversions, we first relocated the earthquakes in southern Taiwan from 1991 up to September 2007 using the new 3D model with station corrections (Wu et al., 2003, 2008b). Our location process determines simultaneously the earthquake locations in the 3D structure as well as the station corrections. It is rather similar to the jointed hypocenter determination (JHD, Dewey, 1971). Our previous experience shows that the consideration of station corrections in the earthquake location process improves the accuracy of the hypocentral determination (Wu et al., 2003). A total of 34,018 earthquakes were relocated. Fig. 5 shows the epicentral distribution of the relocated events as well as the focal mechanisms of the events with magnitudes larger than 4.0 around the Pingtung Earthquake source region (within the box bounded by longitudes $120^{\circ} \mathrm{E}$ and $121.5^{\circ} \mathrm{E}$ and latitudes $21.5^{\circ} \mathrm{N}$ and $22.5^{\circ} \mathrm{N}$ ). The focal solutions are also listed in Table 1. Results for some of the larger events in Fig. 5 and in Table 1 were from the Harvard CMT catalog. For the focal mechanisms obtained in this study, we used the FpSearch program which determines the fault-plane solution by the genetic algorithm to best fit the first-motion polarity observations ( $\mathrm{Wu}$ et al., 2008a). In Fig. 6, the Vp and Vp/Vs structures in the new 3D model are shown for three east-west profiles together with the focal mechanisms and the relocated regional seismicity. Locations of those profiles were indicated in Fig. 5. In general, the seismicity in southern Taiwan can be grouped into three zones. From east to west, the first zone (I) is located at the western side of the Luzon arc, delineating the contact zone of the Luzon arc with the forearc basin. Most of the earthquakes in this zone are shallow and have thrust-fault focal mechanism. The second zone (II) is located between Zone I and the Hengchun Peninsula. There are earthquakes with different types of focal mechanisms in this zone. Normal-fault focal mechanisms occur in the shallow portion, most of which have an extensional axis in EW direction (i.e. parallel to plate motion). Shallow normal-faulting events are commonly related to compressional pop-up or gravitational collapse, and in this case compressional pop-up is more likely considering that the mountainbuilding begins in this region. We suggest that this zone is a young collision and mountain building region. The third zone (III) is located in the western offshore area of the Hengchun Peninsula. Most earthquakes there occur at the depths of $30 \mathrm{~km}$ to $50 \mathrm{~km}$ and have normal-fault focal 
Y.-M. Wu et al. / Tectonophysics $x x x(2009) x x x-x x x$

A
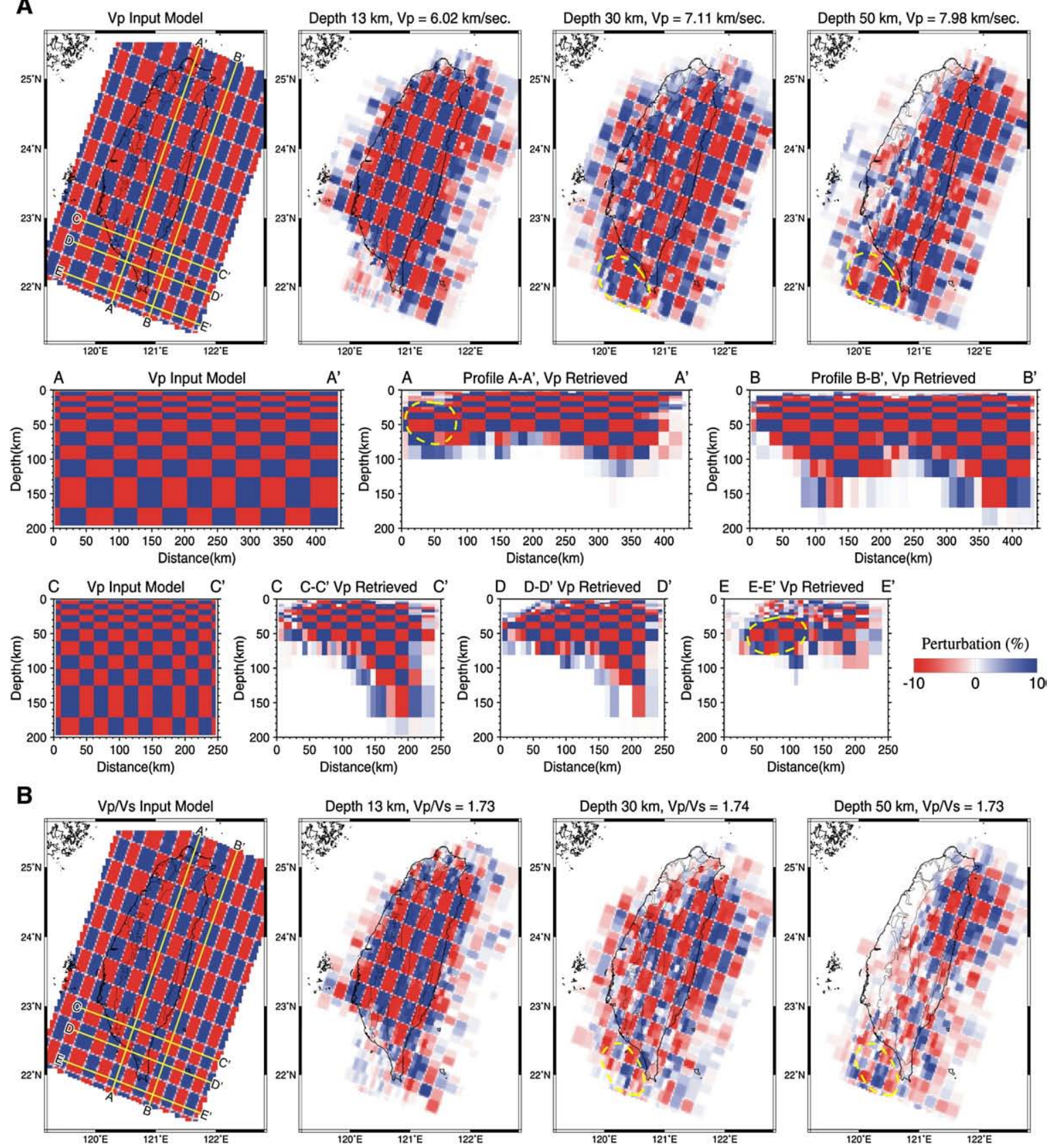

Depth $50 \mathrm{~km}, \mathrm{Vp} / \mathrm{Vs}=1.73$
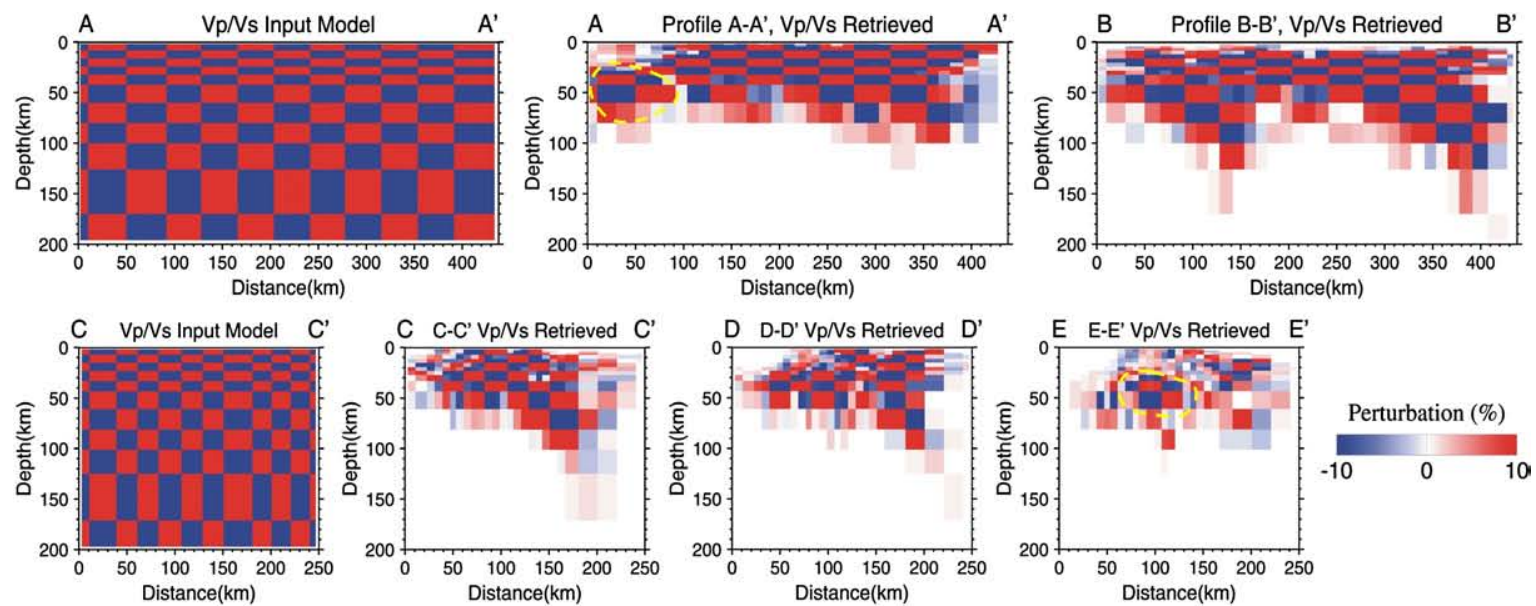

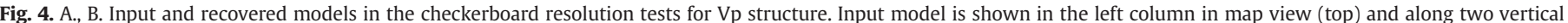

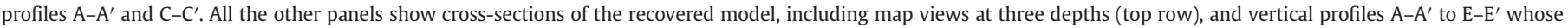

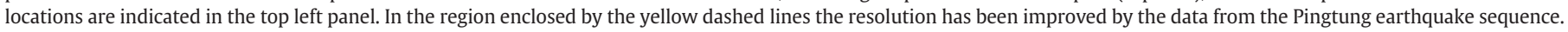
(For interpretation of the references to colour in this figure legend, the reader is referred to the web version of this article.) 


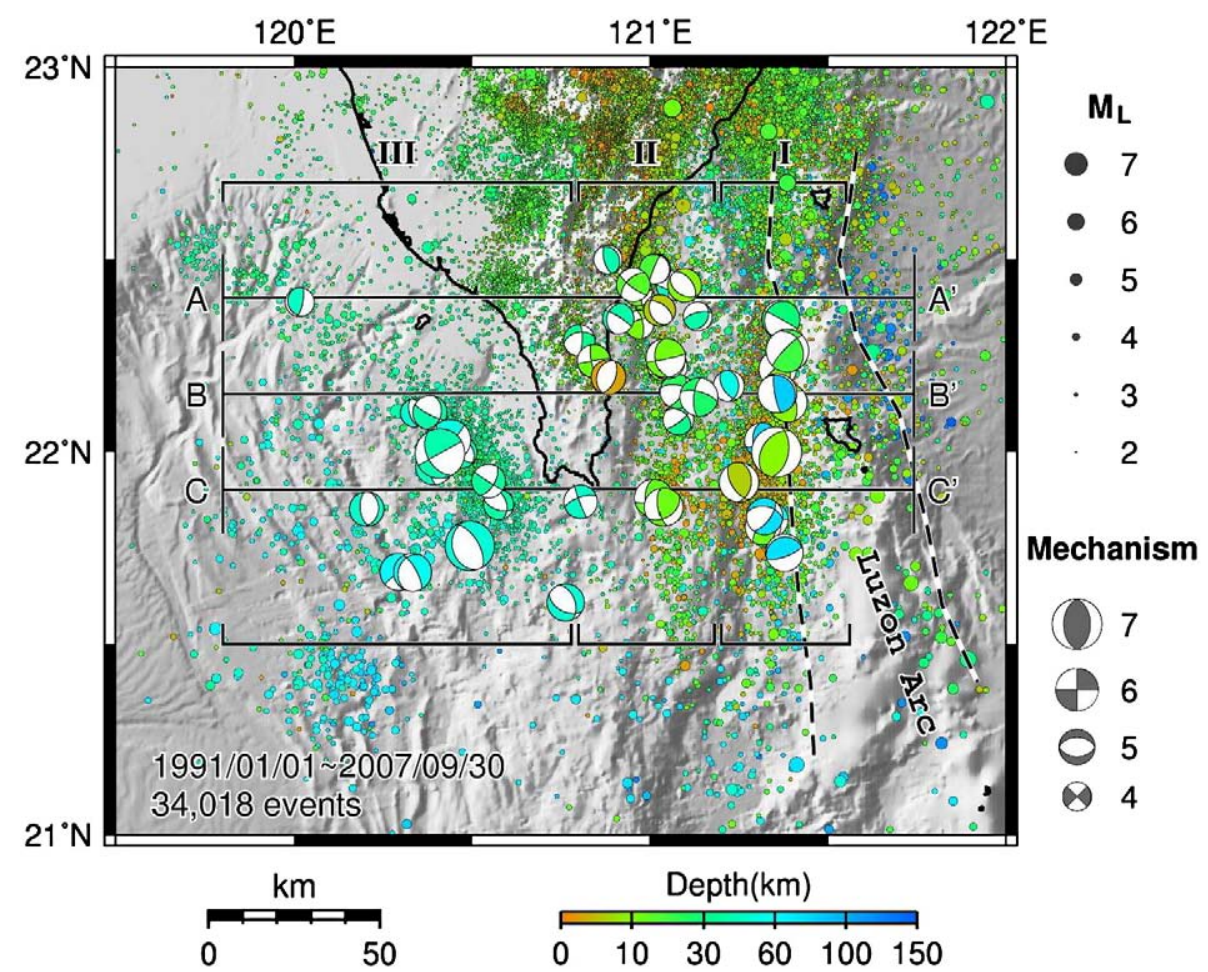

Fig. 5. Distribution of the relocated earthquakes in southern Taiwan and the focal mechanisms for some of the larger events.

mechanism. Those events with normal-fault mechanisms may be associated with the bending of the subducting Eurasian continental lithosphere (Wu et al., 2008a).

In our tomography result, as can be seen in Profiles $\mathrm{AA}^{\prime}$ and $\mathrm{BB}^{\prime}$ in Fig. 6 , the region to the east of the Hengchun Peninsula is characterized by high $\mathrm{Vp}$ in the shallow portion at depths of 0 to $40 \mathrm{~km}$, indicating the oceanic lithosphere of the Philippine Sea Plate. The region to its west is characterized by a thick wedge of either sedimentary rocks or young sediments of low $\mathrm{Vp}$ and high $\mathrm{Vp} / \mathrm{Vs}$, as seen in our previous results (Wu et al., 2007). It is worth noting that the subduction zone south of Taiwan shows a low $\mathrm{Vp}$ region on top of a high $\mathrm{Vp}$ zone. This may be the result of the continental plate subducting beneath an oceanic plate, as suggested by Wang et al. (2006). The continental lithosphere has been split into an upper low Vp layer and a lower high-Vp layer. The lower Vp may also be caused by soft sediments in the accretionary wedge. Profile B-B' in Fig. 6 almost coincides with the TAICRUST Line 33 Profile in McIntosh et al. (2005). The high velocity anomaly under the island imaged in this study can also be seen in McIntosh et al. (2005). The low velocity $(<6 \mathrm{~km})$ in the western offshore of Hengchun Peninsula is thicker in our model than in McIntosh et al. (2005), in which multiple airgun shots over OBSs along a profile are used in imaging. Therefore, McIntosh et al. (2005) has a better resolution at shallow depth. However, the lower Vp zone can be traced from on-land to this region (Wu et al., 2007). It is an important feature that warrants further study.

\section{3D relocation of the Pingtung Earthquake sequence}

A total of 1015 events in the Pingtung Earthquake sequence occurring between 2006/12/26 and 2007/01/31 were relocated using the new 3D velocity model obtained in this study. The arrival times of $\mathrm{P}$ and $\mathrm{S}$ waves from the CWBSN as well as the OBSs and the S-P times from the TSMIP stations were used for the 3D relocation. Fig. 7 shows the distribution of the relocated earthquakes in the Pingtung Earthquake sequence and the focal mechanisms of the doublet earthquakes and the largest aftershock $\left(M_{\mathrm{w}}=5.6\right)$. Two profiles were plotted based on the dip directions of the focal mechanisms of the doublet earthquakes. From the focal mechanism of the first event in the doublet and the hypocentral distribution in Profile $A A^{\prime}$, we propose that the fault plane of the first event is a west-dipping normal fault. Base on its focal depth $(44 \mathrm{~km})$ and the distribution of the aftershocks, it is likely that this is a normal faulting event caused by the bending of the subducting slab. In Profile $\mathrm{BB}^{\prime}$, the distribution of the aftershocks agrees with the strike of the second event and the local geological setting. Obviously, the second event is a strike-slip faulting. Finally, the focal mechanism of the largest aftershock is also a strike-slip event.

\section{Discussion and conclusions}

Combining the arrival times obtained from the OBS records of the Pingtung Earthquake sequence, we updated our regional 3D Vp and $\mathrm{Vp} / \mathrm{Vs}$ models for Taiwan with an enhanced resolution to the structures in southern Taiwan, especially in the near offshore regions. For the on-land region the velocity structure agrees with our previous study (Wu et al., 2007). The updated velocity model was used in relocating the 2006 Pingtung Earthquake sequence. Our results show a low $\mathrm{Vp}$ region with seismicity on top of a high Vp zone in the subduction system south of Taiwan. This suggests the subduction of a continental lithosphere (Lin 2002; Wang et al., 2006) which has been split into two layers with different structures. The exact nature of the plate interaction south of Taiwan will provide the clue to the understanding of the mountain building mechanism in Taiwan, i.e. whether it is the result of an arc-continent collision, an arc-arc collision, a thin skinned collision, a lithosphere collision, or a crustal exhumation (Suppe, 1981; Teng, 1990; Hsu and Sibuet, 1995; Wu et al., 1997; Lin, 2002; Kuochen et al., 2004; Sibuet and Hsu, 2004). If the subduction of the continental lithosphere exists, crustal exhumation may play an important role. However, the focal mechanisms and hypocentral locations of the Pingting Earthquake sequence may contradict this suggestion. The normal-faulting earthquakes may be associated with the bending of the plunging slab. Kanamori (1971) discussed the surface tensile crack due to the bending of the lithosphere. The 
Table 1

Parameters of the focal mechanisms plotted in Fig. 4

\begin{tabular}{|c|c|c|c|c|c|c|c|c|c|c|c|}
\hline No. & Origin time (UT) & Long. (E) & Lat. (N) & Depth (km) & Magnitude $^{\mathrm{a}} M_{\mathrm{L}} M_{\mathrm{W}}$ & Harvard CMT strike dip rake & Fp search strike & Dip & Rake & $Q_{f_{p}}{ }^{b}$ & $\mathrm{Nr}^{\mathrm{C}}$ \\
\hline$\overline{1}$ & 1991/05/11 08:00:43.6 & $121.014^{\circ}$ & $22.476^{\circ}$ & 18.6 & 4.2 & & $202+-9$ & $85+-3$ & $-83+-3$ & 0.27 & 12 \\
\hline 2 & $1991 / 06 / 02$ 19:49:35.8 & $120.016^{\circ}$ & $22.389^{\circ}$ & 46.3 & 4.1 & & $12+-10$ & $74+-18$ & $102+-28$ & 0.42 & 18 \\
\hline 3 & $1992 / 02 / 1800: 33: 51.7$ & $121.060^{\circ}$ & $22.432^{\circ}$ & 46.2 & 4.2 & & $99+-5$ & $65+-20$ & $170+-11$ & 0.56 & 25 \\
\hline 4 & $1992 / 04 / 12$ 21:31:28.5 & $120.470^{\circ}$ & $21.998^{\circ}$ & 42.5 & 4.4 & & $130+-16$ & $63+-1$ & $-94+-6$ & 1.01 & 26 \\
\hline 5 & $1993 / 03 / 05$ 06:57:03.8 & $121.044^{\circ}$ & $22.244^{\circ}$ & 12.1 & 5.5 & & $78+-19$ & $86+-26$ & $136+-27$ & 1.16 & 21 \\
\hline 6 & 1993/03/05 08:25:29.1 & $121.047^{\circ}$ & $22.235^{\circ}$ & 10.3 & 4.9 & & $8+-29$ & $58+-20$ & $109+-23$ & 0.11 & 21 \\
\hline 7 & 1993/03/05 09:12:11.0 & $121.039^{\circ}$ & $22.226^{\circ}$ & 12.0 & 4.6 & & $52+-4$ & $76+-7$ & $117+-13$ & 0.34 & 15 \\
\hline 8 & $1993 / 03 / 0512: 56: 26.5$ & $121.064^{\circ}$ & $22.222^{\circ}$ & 10.7 & 4.0 & & $23+-28$ & $89+-20$ & $85+-18$ & 0.31 & 13 \\
\hline 9 & $1993 / 12 / 06$ 23:00:16.5 & $121.010^{\circ}$ & $21.879^{\circ}$ & 14.4 & 5.35 .4 & 1795520 & & & & & \\
\hline 10 & $1994 / 06 / 11$ 13:30:53.8 & $121.078^{\circ}$ & $22.083^{\circ}$ & 33.5 & 4.3 & & $53+-21$ & $77+-28$ & $-127+-28$ & 0.12 & 14 \\
\hline 11 & 1995/04/09 04:44:51.1 & $121.038^{\circ}$ & $21.855^{\circ}$ & 12.9 & 5.35 .2 & 5545146 & & & & & \\
\hline 12 & $1995 / 06 / 28 \quad 14: 14: 53.8$ & $121.358^{\circ}$ & $22.215^{\circ}$ & 8.8 & 5.35 .3 & 23819174 & $230+-12$ & $81+-14$ & $129+-6$ & 0.21 & 35 \\
\hline 13 & $1995 / 08 / 1123: 52: 57.8$ & $121.027^{\circ}$ & $22.368^{\circ}$ & 6.0 & 4.4 & & $160+-5$ & $39+-3$ & $-63+-9$ & 0.37 & 20 \\
\hline 14 & 1995/09/02 02:23:53.5 & $121.338^{\circ}$ & $21.822^{\circ}$ & 61.0 & 4.9 & & $175+-1$ & $34+-1$ & $-3+-29$ & 0.36 & 29 \\
\hline 15 & 1996/09/05 23:42:07.1 & $121.355^{\circ}$ & $21.999^{\circ}$ & 9.3 & 7.16 .8 & 21441108 & & & & & \\
\hline 16 & 1996/09/06 11:34:34.0 & $121.249^{\circ}$ & $21.920^{\circ}$ & 6.2 & 5.65 .4 & 538120 & & & & & \\
\hline 17 & 1996/12/12 16:04:59.9 & $120.971^{\circ}$ & $22.331^{\circ}$ & 10.9 & 4.0 & & $248+-27$ & $63+-47$ & $155+-22$ & 0.28 & 13 \\
\hline 18 & $1997 / 01 / 02$ 06:31:42.1 & $121.096^{\circ}$ & $22.433^{\circ}$ & 9.2 & 4.7 & & $122+-1$ & $41+-1$ & $-107+-1$ & 0.11 & 22 \\
\hline 19 & 1997/01/03 14:17:06.4 & $121.220^{\circ}$ & $22.171^{\circ}$ & 54.2 & 4.4 & & $149+-15$ & $58+-8$ & $72+-8$ & 0.28 & 14 \\
\hline 20 & $1997 / 01 / 17$ 17:52:54.8 & $120.339^{\circ}$ & $22.101^{\circ}$ & 49.0 & 4.0 & & $162+-44$ & $60+-23$ & $-93+-42$ & 0.69 & 25 \\
\hline 21 & $1997 / 06 / 22$ 09:36:04.3 & $121.387^{\circ}$ & $22.127^{\circ}$ & 9.2 & 5.45 .2 & 3425733 & & & & & \\
\hline 22 & $1997 / 08 / 24$ 12:17:40.3 & $120.294^{\circ}$ & $21.686^{\circ}$ & 59.3 & 5.35 .4 & $52-134$ & & & & & \\
\hline 23 & $1997 / 08 / 2418: 58: 36.9$ & $120.333^{\circ}$ & $21.685^{\circ}$ & 56.8 & 5.35 .3 & $20126-43$ & & & & & \\
\hline 24 & 1997/11/12 00:09:35.3 & $121.377^{\circ}$ & $21.736^{\circ}$ & 74.6 & 5.3 & & $70+-23$ & $73+-1$ & $87+-7$ & 0.26 & 33 \\
\hline 25 & $1998 / 05 / 27$ 10:24:03.9 & $121.133^{\circ}$ & $22.352^{\circ}$ & 39.9 & 4.1 & & $31+-21$ & $31+-16$ & $50+-42$ & 0.24 & 16 \\
\hline 26 & $1998 / 11 / 03$ 07:06:37.7 & $121.136^{\circ}$ & $22.142^{\circ}$ & 26.6 & 5.4 & & $185+-2$ & $68+-9$ & $155+-5$ & 0.37 & 37 \\
\hline 27 & $1999 / 05 / 1803: 43: 22.0$ & $121.357^{\circ}$ & $22.152^{\circ}$ & 85.7 & 5.5 & & $170+-1$ & $79+-7$ & $97+-1$ & 1.38 & 41 \\
\hline 28 & 1999/10/02 22:17:00.8 & $120.884^{\circ}$ & $22.194^{\circ}$ & 2.9 & 4.9 & & $22+-39$ & $57+-20$ & $-86+-2$ & 0.15 & 13 \\
\hline 29 & $2000 / 10 / 2321: 09: 01.6$ & $120.967^{\circ}$ & $22.417^{\circ}$ & 11.6 & 4.1 & & $81+-23$ & $76+-37$ & $-165+-38$ & 1.22 & 15 \\
\hline 30 & 2002/05/10 04:17:13.1 & $121.367^{\circ}$ & $22.344^{\circ}$ & 28.9 & 5.3 & & $299+-15$ & $88+-12$ & $-105+-11$ & 0.94 & 23 \\
\hline 31 & $2002 / 05 / 13$ 13:29:02.3 & $120.575^{\circ}$ & $21.862^{\circ}$ & 39.9 & 4.2 & & $109+-45$ & $60+-22$ & $-126+-45$ & 0.29 & 13 \\
\hline 32 & $2002 / 08 / 28$ 17:05:34.5 & $121.385^{\circ}$ & $22.263^{\circ}$ & 20.5 & 6.05 .6 & 05147 & $224+-23$ & $79+-15$ & $118+-11$ & 0.56 & 44 \\
\hline 33 & $2002 / 12 / 2106: 09: 16.9$ & $121.316^{\circ}$ & $21.803^{\circ}$ & 13.5 & 5.05 .1 & 3473048 & & & & & \\
\hline 34 & $2003 / 05 / 02$ 03:26:00.1 & $120.204^{\circ}$ & $21.850^{\circ}$ & 47.3 & 4.94 .9 & $832-77$ & & & & & \\
\hline 35 & $2003 / 05 / 10$ 05:17:07.6 & $120.802^{\circ}$ & $22.290^{\circ}$ & 33.1 & 4.4 & & $3+-5$ & $74+-11$ & $-136+-34$ & 0.98 & 20 \\
\hline 36 & 2003/07/04 11:48:01.9 & $121.321^{\circ}$ & $21.831^{\circ}$ & 75.0 & 5.2 & & $37+-24$ & $66+-13$ & $-128+-40$ & 0.29 & 31 \\
\hline 37 & $2003 / 08 / 04$ 10:53:23.6 & $120.393^{\circ}$ & $21.961^{\circ}$ & 45.3 & 5.2 & & $174+-26$ & $68+-40$ & $-58+-64$ & 0.53 & 29 \\
\hline 38 & $2003 / 09 / 24$ 01:08:32.1 & $120.547^{\circ}$ & $21.923^{\circ}$ & 36.9 & 4.8 & & $31+-3$ & $61+-14$ & $-3+-58$ & 1.68 & 29 \\
\hline 39 & $2003 / 11 / 21$ 10:59:23.6 & $120.382^{\circ}$ & $22.102^{\circ}$ & 40.5 & 4.8 & & $13+-3$ & $34+-10$ & $-18+-26$ & 0.70 & 21 \\
\hline 40 & $2004 / 08 / 18$ 20:31:40.2 & $121.313^{\circ}$ & $22.030^{\circ}$ & 79.5 & 4.9 & & $67+-39$ & $72+-24$ & $134+-37$ & 0.27 & 33 \\
\hline 41 & $2005 / 01 / 2013: 14: 23.1$ & $121.075^{\circ}$ & $22.157^{\circ}$ & 24.3 & 4.8 & & $29+-8$ & $63+-13$ & $-145+-12$ & 0.56 & 18 \\
\hline 42 & $2005 / 01 / 31$ 10:10:08.3 & $120.954^{\circ}$ & $22.434^{\circ}$ & 16.3 & 4.8 & & $127+-16$ & $78+-25$ & $146+-30$ & 0.53 & 22 \\
\hline 43 & $2005 / 04 / 05$ 11:12:17.1 & $120.912^{\circ}$ & $22.347^{\circ}$ & 39.1 & 4.4 & & $195+-29$ & $27+-28$ & $-19+-27$ & 0.23 & 12 \\
\hline 44 & $2005 / 04 / 1017: 21: 24.7$ & $120.883^{\circ}$ & $22.500^{\circ}$ & 40.9 & 4.1 & & $165+-17$ & $67+-18$ & $96+-13$ & 0.51 & 15 \\
\hline 45 & $2005 / 08 / 30$ 03:42:51.7 & $120.806^{\circ}$ & $21.869^{\circ}$ & 47.1 & 4.7 & & $159+-14$ & $85+-19$ & $-23+-47$ & 0.95 & 20 \\
\hline 46 & 2006/05/07 01:53:01.5 & $120.764^{\circ}$ & $21.606^{\circ}$ & 49.9 & 5.25 .4 & $11849-120$ & & & & & \\
\hline 47 & $2006 / 12 / 2612: 26: 20.9$ & $120.494^{\circ}$ & $21.754^{\circ}$ & 50.9 & 7.07 .0 & $16530-76$ & & & & & \\
\hline 48 & $2006 / 12 / 2612: 34: 14.7$ & $120.410^{\circ}$ & $21.995^{\circ}$ & 41.0 & 7.06 .9 & 151480 & & & & & \\
\hline 49 & $2006 / 12 / 2702: 30: 38.9$ & $120.439^{\circ}$ & $22.030^{\circ}$ & 53.4 & 5.85 .6 & 136709 & & & & & \\
\hline 50 & $2006 / 12 / 28$ 16:51:18.3 & $120.438^{\circ}$ & $22.028^{\circ}$ & 39.5 & 4.6 & & $189+-9$ & $50+-6$ & $-37+-7$ & 0.73 & 20 \\
\hline 51 & $2006 / 12 / 31$ 19:19:39.2 & $120.418^{\circ}$ & $21.989^{\circ}$ & 52.6 & 4.5 & & $60+-31$ & $28+-11$ & $77+-16$ & 1.51 & 31 \\
\hline 52 & $2007 / 02 / 14$ 03:26:16.8 & $120.843^{\circ}$ & $22.236^{\circ}$ & 13.2 & 4.7 & & $169+-4$ & $78+-9$ & $-2+-33$ & 1.43 & 34 \\
\hline
\end{tabular}

${ }^{a} M_{\mathrm{L}}$ from the CWB catalog and $M_{\mathrm{W}}$ from Harvard CMT catalog.

b $\mathrm{Q}_{\mathrm{fp}}$ is the quality factor of first-motion focal mechanism defined by Wu et al. (2008a).

${ }^{c} \mathrm{Nr}$ is the number of polarities used.

large-scale lithospheric faulting is presumably due to gravitational pull exerted by the cold sinking lithosphere. Based on the results from seismic reflection, gravity, magnetism, and bathymetry, Yeh and Hsu (2005) and Hsu et al. (2005) suggested that this region may be a continent-ocean lithosphere transition zone. This could be a reasonable explanation to this contradiction. Wide-angle seismic profiling experiments (McIntosh et al., 2005) suggests that Moho surface in this region can be as shallow as $20 \mathrm{~km}$ or less. However, this depth is clearly below the range in which their data could provide good resolution. Further study is required to resolve this intriguing and important problem.

The distribution of the aftershocks plays an important role in revealing the mechanisms of the main earthquakes. Our relocation of the aftershocks following the Pingtung Earthquake suggests that the first shock of the doublet earthquakes is a west-dipping normal faulting event, perhaps due to the bending of the slab. On the other hand, the second event is a strike-slip faulting (striking northwest) which caused many aftershocks. The largest aftershock in the Pingtung Earthquake sequence is also a strike-slip event.

\section{Acknowledgements}

YMW wishes to thank Profs. Sun-Lin Chung, Francis T. Wu and JerMing Chiu for very constructive comments. We also thank one anonymous reviewer for helpful comments. This research was supported by the Central Weather Bureau and the National Science Council of the Republic of China (NSC95-2625-Z-002-028, NSC952119-M-002-043-MY3, NSC95-2119-M-001-063 and NSC97-2116-M- 

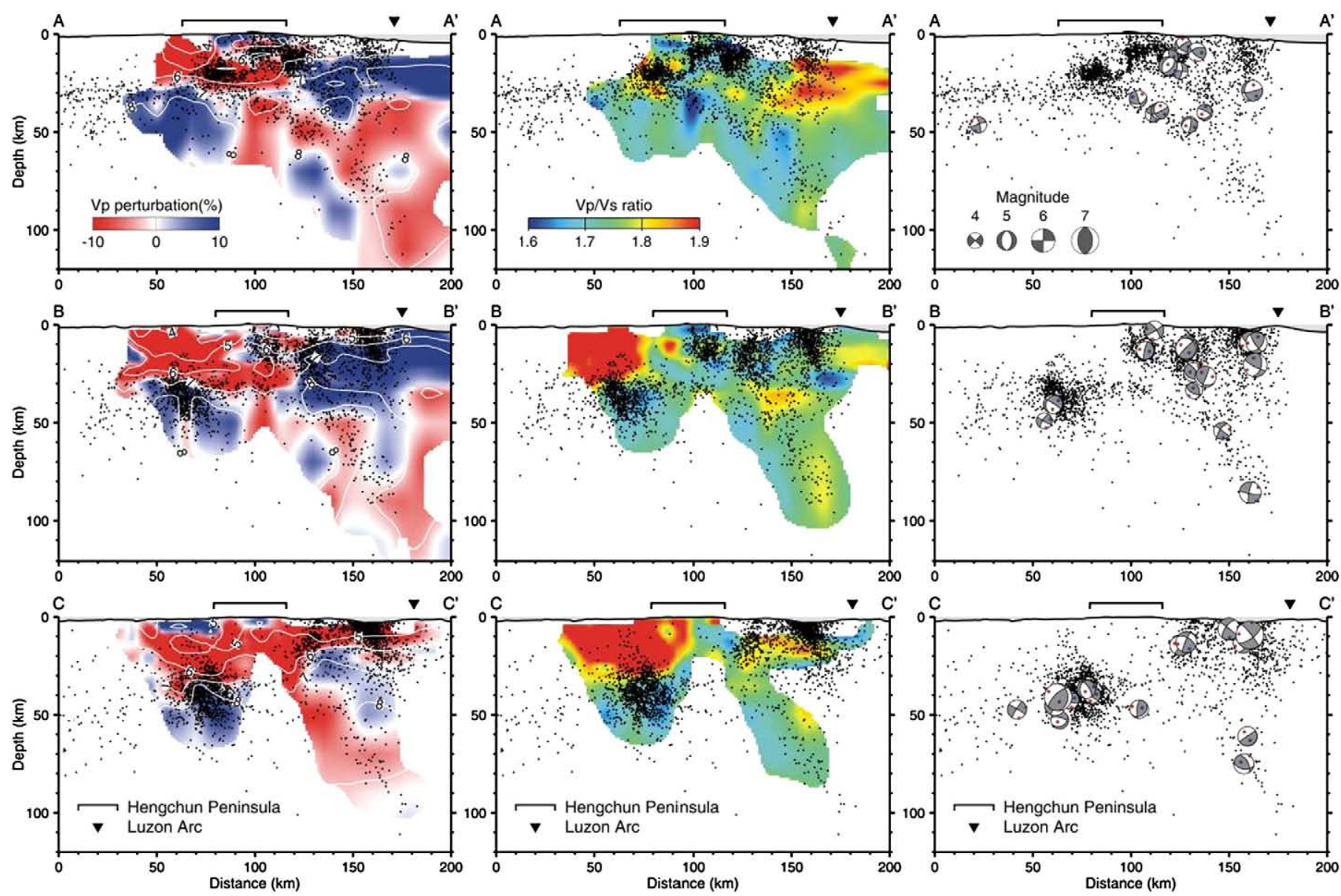

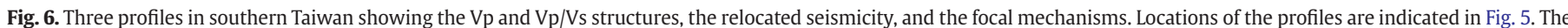

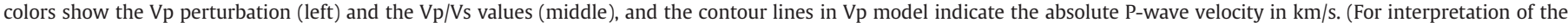
references to colour in this figure legend, the reader is referred to the web version of this article.)

001-016). This manuscript is for the Tectonophysics issue that it is an IGCP 524 publication.

\section{References}

Auffret, Y., Pelleau, P., Klingelhoefer, F., Geli, L., Crozon, J., Lin, J.-Y., Sibuet, J.-C., 2004 MicrOBS: a new generation of ocean bottom seismometer. First Break 22, 41-47.

Dewey, J.W., 1971. Seismicity studies with the method of joint hypocenter determination. Ph. D. Thesis, University of California at Berkeley, 166 pp.

Eberhart-Phillips, D., 1986. Three-dimensional P and S velocity structure in Northern California Coast ranges from inversion of local earthquake arrival times. Bull. Seismol. Soc. Am. 76, 1025-1052.

Eberhart-Phillips, D., 1990. Three-dimensional P and S velocity structure in the Coalinga region, California. J. Geophys. Res. 95, 15343-15363.

Eberhart-Phillips, D., 1993. Local earthquake tomography: Earthquake source regions. In: Iyer, H.M., Hirahara, K. (Eds.), Seismic Tomography: Theory and Practice. Chapmann Hall, New York, pp. 613-643.

Evans, J.R., Eberhart-Philips, D., Thurber, C.H., 1994. User's manual for SIMULPS12 for imaging Vp and Vp/Vs: a derivative of the "Thurber" tomography inversion SIMUL3 for local earthquakes and explosions. USGS Open-file Report 94-431. 100 pp.

Hsu, S.K., Sibuet, J.-C., 1995. Is Taiwan the result of arc-continent or arc-arc collision? Earth Planet. Sci. Lett. 136, 315-324

Hsu, S.K., Yeh, Y.C., Doo, W.B., Tsai, C.H., 2005. New bathymetry and magnetic lineations identifications in the northernmost South China Sea and their tectonic implications. Mar. Geophys. Res. 25, 29-44. doi:10.1007/s11001-005-0731-7.

McIntosh, K., Nakamura, Y., Wang, T.K., Shih, R.C., Chen, A., Liu, C.S., 2005. Crustal-scale seismic profiles across Taiwan and the western Philippine Sea. Tectonophysics 401, 23-54. doi:10.1016/j.tecto.2005.02.015.

National Disaster Prevention and Protection Commission, R.O.C., 2007. Statistics on the Losses on Natural Disaster. http://www.ndppc.nat.gov.tw/.

Kanamori, H., 1971. Seismological evidence for a lithospheric normal faulting - the Sanriku earthquake of 1933. Phys. Earth Planet. Inter. 4, 289-300.

Kim, K.H., Chiu, J.M., Pujol, J., Chen, K.C., Huang, B.S., Yeh, Y.H., Shen, P., 2005. Threedimensional $\mathrm{Vp}$ and Vs structural model associated with the active subduction and collision tectonics in the Taiwan region. Geophys. J. Int. 162, 204-220.
Kuochen, H., Wu, Y.M., Chang, C.H., Hu, J.C., Chen, W.S., 2004. Relocation of the Eastern Taiwan earthquakes and its tectonic implications. Terr. Atmos. Ocean. Sci. 15, 647-666.

Lay, T., Kanamori, H., 1980. Earthquake doublets in Solomon Island. Phys. Earth Planet. Inter. 21, 283-304

Lin, C.H., 2002. Active continental subduction and crustal exhumation: the Taiwan orogeny. Terra Nova $14,281-287$.

Ma, K.F., Wang, J.H., Zhao, D., 1996. Three-dimensional seismic velocity structure of the crust and uppermost mantle beneath Taiwan. J. Phys. Earth 44, 85-105.

Pavlis, G.L., Booker, J.R., 1980. The mixed discrete-continuous inverse problem: Application to the simultaneous determination of earthquake hypocenters and velocity structure. J. Geophys. Res. 85, 4801-4810.

Rau, R.J., Wu, F.T., 1995. Tomographic imaging of lithospheric structures under Taiwan. Earth Planet. Lett. 133, 517-532.

Roecker, S.W., Yeh, Y.H., Tsai, Y.B., 1987. Three-dimensional P and S wave velocity structures beneath Taiwan; deep structure beneath an arc-continent collision. J Geophys. Res. 92, 10,547-10,570.

Sibuet, J.C., Hsu, S.K., 2004. How was Taiwan created? Tectonophysics 379, 159-181.

Suppe, J., 1981. Mechanics of mountain building and metamorphism in Taiwan. Mem. Geol. Soc. China 4, 67-89.

Teng, L.S., 1990. Geotectonic evolution of late Cenozoic arc-continent collision in Taiwan. Tectonophysics 183, 57-76.

Thurber, C.H., 1983. Earthquake locations and three-dimensional crustal structure in the Coyote Lake area, central California. J. Geophys. Res. 88, 8226-8236.

Thurber, C.H., 1993. In: Iyer, H.M., Hirahara, K. (Eds.), Local Earthquake Tomography: Velocities and Vp/Vs-Theory, in Seismic Tomography: Theory and Practice. Chapman and Hall, London, pp. 563-583.

Thurber, C., Eberhart-Phillips, D., 1999. Local earthquake tomography with flexible gridding. Comput. Geosci. 25, 809-818.

Um, J., Thurber, C.H., 1987. A fast algorithm for two-point seismic ray tracing. Bull. Seism. Soc. Am. 77, 972-986.

Wang, Z., Zhao, D., Wang, J., Kao, H., 2006. Tomographic evidence for the Eurasian lithosphere subducting beneath south Taiwan. Geophys. Res. Lett. 33, L18306.

Wu, Y.M., Chen, C.C., 2007. Seismic reversal pattern for the 1999 Chi-Chi, Taiwan, Mw 7.6 earthquake. Tectonophysics 429, 125-132.

Wu, F.T., Rau, R.J., Salzberg, D., 1997. Taiwan orogeny: thin-skinned or lithospheric collision? Tectonophysics 274, 191-220. 

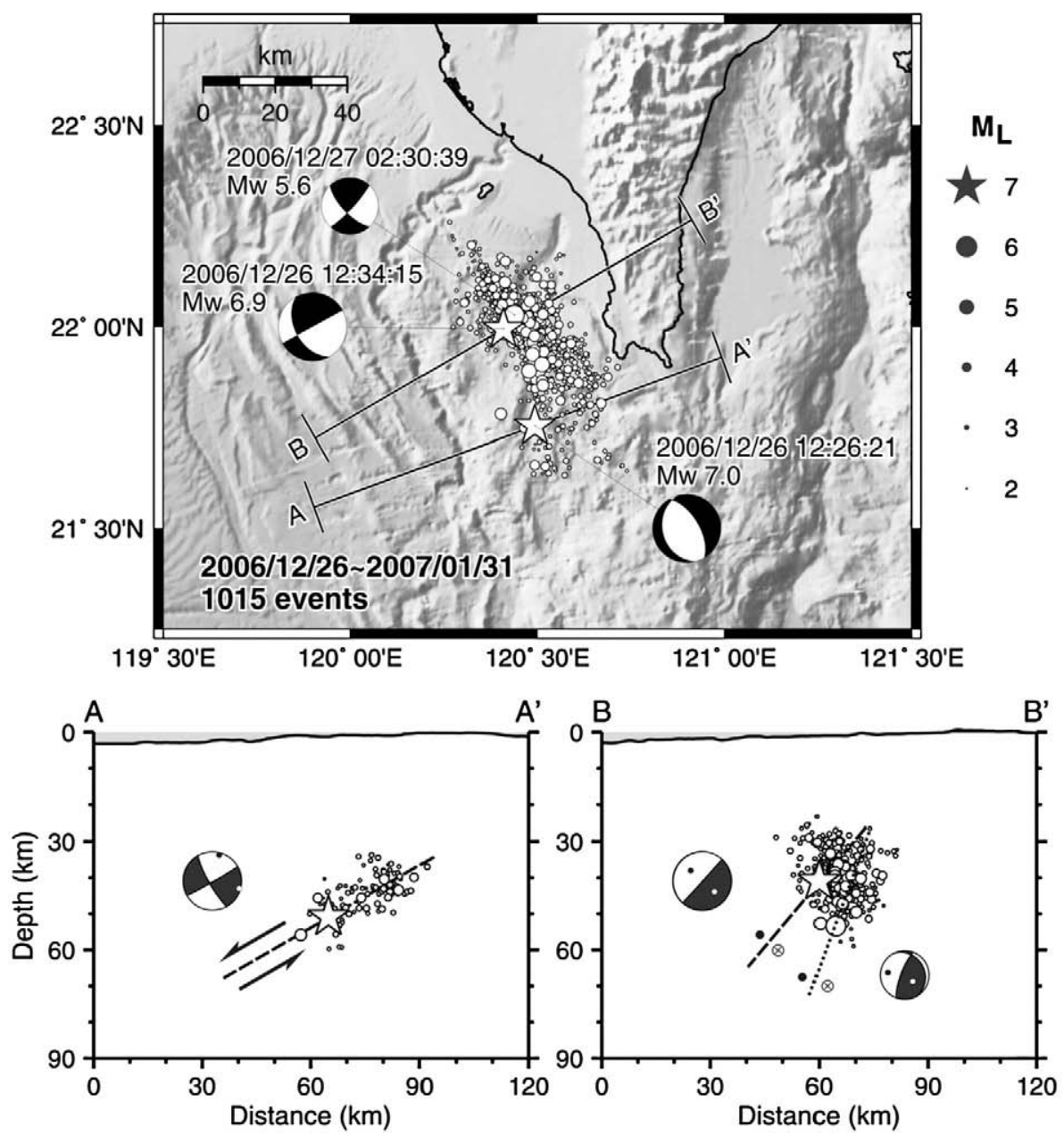

Fig. 7. Distribution of the relocated hypocenters of the Pingtung Earthquake sequence. Stars show the hypocenters of the doublet events.

Wu, Y.M., Chang, C.H., Hsiao, N.C., Wu, F.T., 2003. Relocation of the 1998 Rueyli, Taiwan, earthquake sequence using three-dimensions velocity structure with stations corrections. Terr. Atmos. Ocean. Sci. 14, 421-430.

Wu, Y.M., Chang, C.H., Zhao, L., Shyu, J.B.H., Chen, Y.G., Sieh, K., Avouac, J.P., 2007. Seismic tomography of Taiwan: improved constraints from a dense network of strongmotion stations. J. Geophys. Res. 112, B08312. doi:10.1029/2007JB004983.

Wu, Y.M., Zhao, L., Chang, C.H., Hsu, Y.J., 2008a. Focal mechanism determination in Taiwan by genetic algorithm. Bull. Seism. Soc. Am. 98, 651-661. doi:10.1785 0120070115.
Wu, Y.M., Chang, C.H., Zhao, L., Teng, T.L., Nakamura, M., 2008b. A comprehensive relocation of earthquakes in Taiwan from 1991 to 2005. Bull. Seism. Soc. Am. 98, 1471-1481. doi:10.1785/0120070166.

Yeh, Y.C. Hsu, S.K., 2005. Crustal structures of the northernmost South China Sea: seismic reflection and gravity modeling. Mar. Geophys. Res. 25, 45-61. doi:10.1007| s11001-005-0732-6. 